Масиха Низар Юнис

аспирант кафедры социологии

Российского университета дружбы народов

\section{СОЦИАЛЬНЫЕ АСПЕКТЫ ИННОВАЦИОННОГО ПОТЕНЦИАЛА ОРГАНИЗАЦИЙ}

Masikha Nizar Yunis

PhD student, Department of Sociology, Peoples' Friendship University of Russia

\section{SOCIAL ASPECTS OF THE INNOVATIVE CAPACITY OF COMPANIES}

\section{Аннотация:}

В связи с активным развитием технологического процесса все более актуальными становятся вопросы создания инноваций. Современная экономическая практика показывает, что значительных успехов в формировании и развитии инновационных продуктов достигают частные организации. При этом, несмотря на перспективы успешной коммерциализации данной сферы, имеют место существенные риски и высокая вероятность неудачи инновационных проектов. Поэтому большое значение приобретает поиск подходов, позволяющих повысить эффективность инновационного процесса для организаций и снизить его риски. С этой целью в статье осуществлена попытка проанализировать главные социальные аспекты инновационного потенциала предприятий, оценка которых может помочь частным фирмам оценить собственные перспективы в области инновационных технологий. Описаны особенности научного и социологического понимания инноваций, их дифффузии, инновационных потоков и инновационного ме неджмента. На этом основании выделены социальные аспекты инновационного потенциала организаций и предложены методы их оценки.

Ключевые слова:

инновация, инновационный потенциал организации, инновационный менеджмент, управление инновациями.
Keywords:

innovation, innovative capacity of the company, innovative management, management of innovations.
Due to the active development of the technological pro cess, the issues of creating innovations become more urgent. Modern economic practice shows that private organizations make progress in the creation and development of innovative products. Despite the prospects of successful commercialization of the latter, there are the significant risks in and a high probability of innovative projects failing. Therefore, it is pivotal to find approaches that enhance the effectiveness of the innovation process for companies and reduce its risks. To this end, the study analyzes the main social aspects of the company's innovative capacity that can help private companies assess their prospects for innovative technologies. The research presents the scientific and sociological understanding of innovations, their diffusion, innovation flows and innovative management. On that ground, social aspects of the company's innovative capacity are highlighted and their assessment methods are proposed.

Процессы, связанные с развитием новых технологий, неоднородны и разнонаправленны, что значительно усложняет их анализ. Например, участники Consumer Electronics Show (Meждународной выставки потребительской электроники, далее - CES) 2016 г. отметили отсутствие действительно новых решений в технике, представленной ведущими мировыми компаниями [1]. Мнения экспертов об итогах мероприятия были довольно критичны и содержали выводы о стагнации сфреры инновационных разработок. При этом отзывы о CES 2017 г. [2], несмотря на аналогичную ситуацию с представленными продуктами, были более оптимистичные. Большинство специалистов сошлись в оценке, что производители не перестали создавать новые технологии, а сменили вектор инновационного развития. Причины этого явления объяснялись, во-первых, завершением одного инновационного цикла и началом другого, во-вторых, изменением общественного представления об инновациях. Любопытно, что если год назад эксперты были настроены скептически из-за снижения интенсивности развития в сфере потребительской техники, то сегодня они видят в этом же процессе зарождение новой волны разработок. Из этого частного примера видно, что вопросы, связанные с созданием универсальной методологии анализа инновационного развития общества, крайне сложны и очень далеки от полноценного решения. Это формирует потребность их комплексной и всесторонней разработки.

Тем не менее можно с уверенностью говорить, что сегодня все большее значение приобретают не только количественные характеристики инноваций, но и качественные. В потребительской технике они связаны с возможностью технологического решения взаимодействия пользователя с другой принадлежащей ему техникой или устройствами его социального окружения; простотой использования; степенью защиты; способностью к самообучению и т. д. В фундаментальных исследованиях сложнее выделить конкретные направления развития, но явно вырисовыва- 
ется потребность в объединении деятельности разных научных сфер и более эффективной коммуникации с общественными и хозяйственными системами, влияющими на инновационное развитие. Учитывая, что потребительские и фундаментальные инновации связаны между собой, а также принимая во внимание воздействие на инновации социокультурных и экономических фракторов (иначе - диффузию инноваций), можно говорить о необходимости анализа инновационных процессов в фокусе институционального взаимодействия.

Тенденции современного новаторства (как фундаментального, так и потребительского) связаны с конвергенцией. Любая сложная технология требует взаимодействия с рядом других, что предполагает высокий уровень сотрудничества и доверия между разработчиками, инвесторами, контролирующими органами, рынками, потребителями и обществом в целом.

Особенный интерес вызывают взаимосвязи бизнеса и инноваций, так как многие частные компании добились успехов посредством создания новых продуктов/услуг, но при этом путь инновационного развития все равно является спорной стратегией для конкурентного бизнеса. Это связано с тем, что создание и внедрение новых технологий представляет собой многофакторный процесс с относительно невысоким шансом вернуть инвестиции и получить прибыль. Очевидно, что инновации дают организационной структуре преимущества, но сама процедура разработки и ввода в эксплуатацию нововведения, наоборот, снижает устойчивость социально-экономической системы, а также увеличивает риски. У данного свойства есть ряд оснований: аналитические инструменты не позволяют дать полноценный прогноз окупаемости нововведения; не всегда понятно, насколько сама организация готова к производству или внедрению инновации; имеют место проблемы, связанные с дифффузией инноваций; неожиданной может стать реакция потребителя на новый продукт/услугу; конкуренты практически без затрат пользуются опытом компании-инноватора и др.

Поэтому предпринимателям не всегда выгодно и безопасно создавать новые технологии. При этом многие успешные инновационные компании, опираясь на поддержку государства и благоприятную социально-экономическую среду, являются полностью частными и имеют успех, что позволяет говорить о значимости инновационной активности бизнеса для развития новаторских технологий.

Существует ряд рыночных механизмов снижения рисков и повышения эфффективности деятельности частных инновационных предприятий. Среди них можно выделить краудфандинг (от англ. crowd - 'толпа', funding - ‘финансирование') - механизм, позволяющий собирать целевые пожертвования на создание какого-либо объекта, интересного для конкретного пользователя. «Инвестором» в данном случае обычно выступает физическое лицо, а само вложение чаще всего финансово не окупается. Сумма такой инвестиции-пожертвования редко превышает 10-20 долл. и делается чаще для поддержки проекта, а не заработка. Посредством подобного подхода были неоднократно профинансированы относительно недорогие разработки изобретателей-одиночек и небольших творческих групп инноваторов. Гораздо реже к краудфандингу прибегают крупные компании, а краудфандинговые проекты, как правило, носят бытовой или развлекательный характер.

Крупные корпорации используют так называемые инновационные потоки - подход, в рамках которого инновационная технология разделятся на ряд продуктов, поступающих на рынок согласно установленным интервалам. Яркий пример работы данного инструмента - мобильный телефон марки iPhone компании Apple. Незначительно, но фрактически улучшая каждую последующую модель, Apple coхраняет высокие доходы от продажи продукта уже более 10 лет. Помимо этого существуют варианты венчурного финансирования, упрощенные формы налогообложения, инвестиционные проекты и т. д. Данные механизмы позволяют повысить эффективность развития инноваций, но решают только денежные вопросы и чаще всего направлены на технологии широкого потребления.

Финансовый аспект является важным, но не единственным фактором развития нововведений из ряда других. Создание новых технологий становится крайне затруднительным без наличия специалистов нужного уровня, налаженных связей со стейкхолдерами, взаимодействия с наукой и образованием, эффрективной культуры труда и производства, особенного правового статуса и т. д. Делая упор только на финансовые инструменты, сложно разработать передовые технологические системы, поэтому в процессе развития новаций нужно уделять значительное внимание следующим фракторам: особенностям инфраструктуры, коммуникации между заинтересованными сторонами, социокультурным аспектам взаимодействия и производственной деятельности [3].

Анализируя проблематику управления инновациями, можно сделать следующие выводы.

1. Инновационный процесс является цикличным, при этом смена циклов может иметь скачкообразный и революционный характер.

2. Инновации становятся эффективными для предпринимателей, если реализуются с позиций «инновационного потока», суть которого заключается в порционном и периодичном выпуске новых моделей продукта/услуги на рынок. Важно, чтобы следующая модель продукта незначительно, но фактически улучшала старую.

3. Этап «инновационного потока» цикла жизни инновации всегда заканчивается. Перед его завершением обычно наблюдается высокая рентабельность деятельности в рамках реализации инновационного продукта/услуги, которая переходит в фразу спада и оканчивается кризисом и депрессией отрасли. 
4. Эффрективность управления инновационным процессом определяется как показателями реализации инновационного продукта, так и потерями, понесенными после завершения одного «инновационного потока» и начала другого.

5. Инновационный процесс несет в себе много рисков. Потенциальная степень их значимости и масштабности определяется диффузией инноваций [4].

Компании, поставившие перед собой задачи создания инновационных продуктов, должны иметь максимально полноценное представление о своем инновационном потенциале. Особое внимание здесь следует уделить готовности социальной среды организации к формированию инновации, так как именно сотрудники, являющиеся носителями человеческого и социального капитала, выступают не только объектом управленческого воздействия, но и одним из ключевых субъектов создания инновационных разработок.

Для того чтобы сфрормулировать подходы к оценке инновационного потенциала организации, следует более четко определить само понятие «инновация». Термин «инновация» может рассматриваться как процесс, технология, идея, система, метод, изменение, результат и др. Также под ним понимается абсолютно или относительно новое, имеющее субъект и объект. Инновация должна быть целерациональна, технически и технологически обоснованна.

Посредством общего анализа социологического подхода к инновационному процессу можно выделить следующие характерные черты, свойственные пониманию нововведений в рамках исследований социальных систем.

1. Инновационная деятельность обычно выступает в форме отклонения от нормы. Развитие идеи о том, что девиация может служить социальным фактором изменений и инноваций, было отражено в работах Р. Мертона [5]. Он выделял четыре типа отклоняющегося поведения: мятеж, ретритизм, ритуализм, инновацию.

2. Инновационная деятельность чаще всего сталкивается с сопротивлением, причиной которого может быть конкуренция с устоявшимися традициями. Возможны как естественная замена старого на новое, так и нормативное управленческое воздействие в рамках перехода к нововведениям.

3. Не следует применять жестких мер при переходе к инновациям путем административной отмены традиций. Эффрективным шагом является приведение социальной среды к состоянию, которое обеспечивает наиболее сбалансированный процесс перехода от старого к новому, когда инновация для общества представляется не ломкой традиционного, а логическим развитием. Чтобы определить степень готовности социальной среды, требуется использовать исследовательские практики в рамках социологии, экономики, социологии управления и др.

4. Для понимания инновационного потенциала организации необходим многофакторный анализ социальной среды на предмет ее готовности к нововведениям.

Существуют два вида диффузии инноваций.

- Экономическая диффузия - степень проникновения инновации в производственные сфреры, фринансовый сектор, рынки, а также в потребительские взаимоотношения. Перед внедрением следует оценить потенциал экономической диффузии для конкретной инновации.

- Социальная дифффузия - степень проникновения инновации в социокультурную среду. Перед внедрением нужно оценить потенциал социальной диффузии для инновации.

С.Ю. Глазьев выделяет следующие факторы, влияющие на диффузию инноваций: очевидность преимущества нового решения; совместимость со сложившейся практикой хозяйствования, техникой и технологиями; сложность новшества; опыт внедрения [6].

Диффузия инновации имеет принципиальное значение для инновационного управления. При этом все ее факторы подчинены специфике социальной системы, в которой реализуется инновация.

Для полноценной реализации инновационного потенциала организации требуется системное применение инструментов инновационного менеджмента, который должен быть частью общей системы организационного управления. Особое внимание в данном случае должно уделяться социальным аспектам, так как они в прямой или косвенной форме оказывают влияние на все стороны инновационного процесса компании.

Для инновационного менеджмента наибольшее значение имеют следующие свойства социальной среды организации: особенности корпоративной культуры в контексте социальной диффузии инноваций; система мотивации и поощрения инновационных инициатив сотрудников; уровень компетентности работников предприятия; личная заинтересованность персонала в реализации инновационного проекта; понимание руководством необходимости создания и развития инноваций, а также активное участие в инновационном проекте и неформальная заинтересованность в нем; эффективное взаимодействие с внутренними и внешними заинтересованными сторонами инновационного проекта и др.

Для анализа и оценки инновационного потенциала организации в рамках инновационного менеджмента рекомендуется обратить первоочередное внимание на следующие социальные аспекты. 
1. Социальный состав и социальная структура компании. В данном аспекте следует определить основные критерии социального состава предприятия (половозрастные характеристики сотрудников; длительность работы в должности, организации и отрасли; соотношение управленческого, производственного и обеспечивающего персонала и др.), а также особенности системы взаимодействия и коммуникаций внутри организации. Провести оценку социального состава и социальной структуры организации можно посредством социологических опросов, наблюдений, а также анализа документов, коммуникаций и бизнес-процессов.

2. Мнение сотрудников о готовности организации к созданию инновации. Данный фактор оказывает значительное влияние на эффеккивность инновационного процесса в организации. Если работники считают, что компания не может (не должна) реализовывать инновационный процесс, то даже в случае ее полноценной готовности к разработке инновации имеет место значительный риск неудачи. Оценка мнения персонала может быть осуществлена посредством социологических методов (опросов в формате интервью или анкетирования).

3. Готовность сотрудников организации к созданию инновации. Показатель можно условно разделить на профрессиональную готовность (наличие необходимых профеессиональных компетенций), личностную (наличие у работников человеческих качеств, позволяющих участвовать в инновационном процессе), социальную (наличие в организации корпоративной культуры, в рамках которой возможны создание и развитие инноваций). Анализировать данный аспект можно посредством специализированных способов оценки персонала (например, с помощью методов «360 градусов», «ассессмент-центр» и др.), а также стандартизированных методик исследования корпоративной культуры (в частности, техники К. Кэмерона, Р. Куина).

4. Готовность руководства организации к созданию и внедрению инновации. Данный принцип является одним из важнейших для раскрытия инновационного потенциала предприятия, так как без личной заинтересованности руководства в инновации значительно снижается вероятность ее успешной реализации. Оценить этот аспект можно посредством лейтмотивного, неструктурированного интервью или в рамках проведения стратегической сессии внутри компании [7].

Увеличение количества инновационных организаций представляет собой важнейший элемент современного государственного управления и общественного развития. Механизмы создания компаний, разрабатывающих инновации, предполагают наличие особых социальных, экономических и культурных условий. Изучая опыт легендарной Кремниевой долины, можно выделить следующий кейс: еще в середине 1990-х гг. Аpple создала систему управления процессами под названием ANPP (Apple New Product Process - процесс разработки нового продукта Apple). Этот подход предполагал комплекс взаимосвязанных стандартизированных методик в рамках производства и внутриорганизационных коммуникаций. Данная система позволила Apple преодолеть кризисы, связанные с проблемами фирмы, имеющими место с конца 1980-х гг., и сформировать базу для создания прорывных технологий, которые позволили ей стать самой дорогой компанией мира. Систему ANPP не удалось бы создать без использования инновационного потенциала социальной среды предприятия [8, с. 181-182].

Оценка инновационного развития общества контекстуальна: в один временной период инновационной будет считаться разработка, имеющая длительный срок службы и невысокую цену, в другой критерий новизны может определяться как маркетинговое качество и удобство использования технологии (так называемое usability), в третий новизна будет предполагать фундаментальное значение новшества. В связи с этим новаторство является нелинейным и слабо поддающимся изучению процессом. Ссылаясь на возможность копирования лидерских технологий, можно вспомнить цитату, приписываемую Г. Форду: «Если бы я спросил людей, чего они хотят, то они бы попросили более быструю лошадь», которая подчеркивает ограниченность исключительно количественного понимания процесса развития инноваций. Кроме того, если создание изобретения несет в себе творчество, нестандартность мышления и расширение границ допустимого, то внедрение новации в общественную, экономическую, производственную и правовую сферы предполагает стандартизацию и строгое администрирование. Помимо этого большое влияние оказывают окружение и заинтересованные стороны. Социальная среда организации позволяет объединять эти часто разрозненные элементы в одно направление. На сегодняшний день оно является хоть и далеким от идеала, но действенным механизмом развития инновационных процессов и реализации государственной стратегии инновационного развития.

Эксперты ожидают, что в обозримом будущем на CES будут представлены новые технологии, разработанные в рамках очередного цикла инновационного развития [9]. Это означает, что производственные и деловые системы ждут изменение и оптимизация. Поэтому использование социально-экономических инструментов инновационного развития становится все более важным. 


\section{Ссылки:}

1. Вильянов C. CES 2016: Почему самая большая выставка электроники осталась без новинок? [Электронный ресурс] // Bankir.ru. URL: http://bankir.ru/publikacii/20160107/ces-2016-pochemu-samaya-bolshaya-vystavka-elektroniki-ostalas-beznovinok-10007067 (дата обращения: 13.12.2017).

2. Вильянов С. Все, что не случилось в Вегасе. Заметки о CES 2017 [Электронный ресурс] // Taм же. URL: http://bankir.ru/publikacii/20170111/vse-chto-ne-sluchilos-v-vegase-zametki-o-ces-2017-10008453 (дата обращения: 13.12.2017)

3. Hobbs K.G., Link A.N., Scott J.T. Science and technology parks: an annotated and analytical literature review // Journal of Technology Transfer. 2017. No. 4 (42). P. 957-976 ; Hyde A. Working in Silicon Valley: economic and legal analysis of a high velocity labor market. Abingdon; N. Y., 2016.

4. Неверов А.В., Дудник А.С. Социальные аспекты инновационного управления организацией // Вестник РУдН. Сер.: Социология. 2014. № 4. С. 151-160.

5. Мертон Р. Социальная теория и социальная структура. М., 2006.

6. Глазьев С.Ю. Теория долгосрочного технико-экономического развития. М., 1993.

7. Неверов А.В., Дудник А.С. Указ. соч.

8. Кани Л. Джони Айв. Легендарный дизайнер Apple. М., 2014. С. 181-182.

9. Вильянов С. Все, что не случилось ...

\section{References:}

Glazyev, SYu 1993, Theory of long-term technical and economic development, Moscow, (in Russian)

Hobbs, KG, Link, AN \& Scott, JT 2017, 'Science and technology parks: an annotated and analytical literature review', Journal of Technology Transfer, No. 4 (42), pp. 957-976. https://doi.org/10.1007/s10961-016-9522-3.

Hyde, A 2016, Working in Silicon Valley: economic and legal analysis of a high velocity labor market, Abingdon, New York. Kahney, L 2014, Jony Ive: The genius behind Apple's greatest products, Moscow, pp. 181-182, (in Russian).

Merton, R 2006, Social theory and social structure, Moscow, (in Russian).

Neverov, AV \& Dudnik, AS 2014, 'Social aspects of company's innovative management', Vestnik RUDN. Ser.: Sotsiologiya, no. 4, pp. 151-160, (in Russian).

Villyanov, S 2017a, 'CES 2016: Why there were no novelties on the largest electronics exhibition?', Bankir.ru, viewed 13 December 2017, <http://bankir.ru/publikacii/20160107/ces-2016-pochemu-samaya-bolshaya-vystavka-elektroniki-ostalas-beznovinok-10007067>, (in Russian).

Villyanov, S 2017b, 'Everything that did not happen in Vegas. Notes on CES 2017', Bankir.ru, viewed 13 December 2017, <http://bankir.ru/publikacii/20170111/vse-chto-ne-sluchilos-v-vegase-zametki-o-ces-2017-10008453>, (in Russian). 